\title{
Genetic diversity in a historic lime tree allée of Széchenyi Castle in Nagycenk, Hungary
}

\author{
Endre Gy. Tóth ${ }^{\mathbb{D}} \cdot$ Kinga Szilágyi $(\mathbb{D}$ - \\ András Patyi $\cdot$ Zsuzsanna György
}

Received: 2 August 2021 / Accepted: 20 January 2022 / Published online: 5 February 2022

(C) The Author(s) 2022

\begin{abstract}
Trees are key components of historic gardens and are valuable sources of genetic diversity that need preservation to enrich native populations' genetic basis in order to enhance long-term viability, and facilitate the species' adaptation to changing climatic and environmental conditions. The primary objective of our study was to assess the genetic diversity, structure and relationships of the Tilia cordata Mill. allée at Széchenyi Castle in Nagycenk (UNESCO heritage site), Hungary, to infer the lateBaroque garden's rich genetic heritage and conservation importance. The small leaved lime individuals at Nagycenk, with an age of 200 years, maintained high genetic diversity with non-significant inbreeding and high allelic richness and number of private alleles. Genetic diversity was similar to Central European
\end{abstract}

\section{E. G. Tóth}

Forest Research Institute (FRI), University of Sopron (UOS), Várkerület 30/a, Sárvár 9600, Hungary

e-mail: toth.endre@uni-sopron.hu

\section{K. Szilágyi}

Doctoral School of Landscape Architecture and Landscape

Ecology, Hungarian University of Agriculture and Life

Sciences, Villányi út 35-43, Budapest 1118, Hungary

e-mail: mezosne.szilagyi.kinga@uni-mate.hu

\section{A. Patyi · Z. György $(\bowtie)$}

Institute of Genetics and Biotechnology, Department of Plant Biotechnology, Group of Horticultural Plant Genetics, Hungarian University of Agriculture and Life Sciences, Ménesi út 44, Budapest 1118, Hungary e-mail: benyone.gyorgy.zsuzsanna@uni-mate.hu natural populations and slightly higher compared to other plant collections, e.g. Eszterházy Castle garden at Fertôd. The surveyed trees exhibited two age groups unrelated with shallow genetic differentiation indicating the potential seed source origin from the local geographic area. Bayesian clustering of individuals showed significant differences from the individuals growing at Fertőd-Esterházy gardens (approx. in a $15 \mathrm{~km}$ distance) and other T. cordata cultivars. We concluded that the $T$. cordata collection of Nagycenk is a unique genetic heritage of the former natural vegetation due to its genetic variability and divergence, which would be a valuable source of future breeding programs and conservation.

Keywords Lime tree $\cdot$ Microsatellite . Polymorphism - Tilia cordata - Genetic heritage . Late-Baroque lime tree allée

\section{Introduction}

The importance of historic gardens in preserving genetic diversity is widely recognised. Consequently, the cultivation of living plants in exsitu collections has been going on for a long time (Miller 2004; Wolff et al. 2019). Plant collections can avoid the harmful effects of human population growth (anthropogenic activities), adverse industrial effects, ecological/biological threats and natural disasters (Edwards and Jackson 2019). 
Artificial populations are capable of maintaining genetic diversity for the long term, preserving the genetic fitness of individuals and populations to maintain population size, especially in case of species experiencing a decline in genetic variation and increasing inbreeding as well as the risk of extinction (Frankham and Ralls 1998; Frankham 2005). Also, they represent genetic variability of current or former natural populations while preserving alleles specific to the geographic region (Potter et al. 2017). Plant collections in historical gardens consist of not only herbaceous plants but also forest tree species. In particular, ancient or veteran forest trees are of biological, aesthetic and cultural interest due to their age and size (Ciaffi et al. 2018). Such species and their individuals require a high level of genetic variation to adapt to changing environmental effects because they are long-lived, stationary, and often widespread life forms compared to other plants (Potter et al. 2017).

Small-leaved lime (Tilia cordata Mill.) is a longlived forest tree native to most parts of Europe, and it is the most widespread among the other Tilia species (Eaton et al. 2016). The species is a lowland tree with an extensive geographical range; it tolerates a vast range of climatic conditions (Pigott 2012). Nowadays, its occurrence in natural sites is rare and scattered, mostly found in mixed stands. However, lime is frequently planted in urban areas as shade and ornamental and street trees (Eaton et al. 2016; Fineschi et al. 2003). Regeneration can either happen from generative or vegetative reproduction, though many factors hamper sexual reproduction. For example, fertilisation is very sensitive to temperature, while seed ripening is more exposed to nutrient availability. However, $T$. cordata regenerates from vegetative reproduction, which is a life strategy of the genus Tilia. The species produces clump shoots and sprouts and thus ensures a much longer lifetime as sprouts can replace the old, dying parent tree (De Jaegere et al. 2016).

The lime tree allée of Nagycenk, which belongs to the Széchenyi Castle, was planted between 1754 and 1760. Today the area is part of the Fertó/Neusiedlersee Cultural Landscape UNESCO World Heritage Site (Harlov-Csortán, 2017) and is managed by the Eszterháza Cultural Centre. In addition, it is a nature conservation area and a landscape value protected by the Fertő-Hanság National Park, Hungary (Gerzson et al. 2012).
Initially, around 600 individuals, mostly Tilia cordata, were planted from propagating material of unknown origin, most probably seedlings from the surrounding forests. However, today this number has decreased significantly; the allée consists of 499 individuals, including many replacements as well. According to previous surveys (Gerzson and Szilágyi 2011), about $20 \%$ of today's individuals are still from the original planting or a very early replantation. Nowadays replanting and full allée renewal are becoming more and more urgent due to the deteriorating health of the trees. According to the assessment performed in 2018, the deterioration process is rapidly proceeding. Even though the life span of T. cordata can reach up to 1000 years, the first signs of rot inside the trunk may occur at around 250 years (De Jaegere et al. 2016). On the other hand, the original stem can be retained for approximately 300 years (Pigott 1989). Therefore, it will be necessary to renew the allée in the near future. Consequently, it is crucial to be aware of the genetic composition of the current and the original stock, as this knowledge may affect the renewal's planting strategy and especially the propagating material for replantation.

Genetic diversity within the genus Tilia has been assessed only in a few studies using different molecular markers. The first studies aimed at determining parents of hybrids, differentiation within and among populations. The development of molecular markers is apparent, just as in the case of any other plant species. The early studies have been performed by RFLP (Fineschi et al. 2003) and allozymes (Fromm and Hattemar 2003). The next choice of marker system was RAPD (Liesebach and Sinkó 2008; Hosseinzadeh Colagar et al. 2013). Nuclear rDNA ITS was used for species differentiation by Yousefzadeh et al. (2012). The first set of microsatellite markers have been developed for T. platyphyllos by Phuekvilai and Wolff (2013); they also reported the markers' transferability to other Tilia species. Later the same research group used these SSR markers successfully for assessing genetic diversity in populations of T. platyphyllos and T. cordata (Logan et al. 2015). Mylett (2015) developed SSR markers for T. cordata, and also in that study, transferability to $T$. platyphyllos was reported.

According to our hypothesis, in addition to the cultural and historical significance of the lime tree allée of Nagycenk, Hungary, it can also represent an outstanding value from the gene conservation point of 
view, being an ex-situ gene reserve for an essential European tree species. Therefore we aimed to assess the genetic diversity of the allée with SSR markers.

\section{Material and methods}

Plant material and sampling strategy

In 2018, a detailed visual and instrumental tree assessment of the Nagycenk allee created the scientific fundaments for the allée renewal (Szilágyi and Szabó 2020). Based on the tree survey, 72 old lime trees have been selected in the present study. The trees chosen have been estimated to be around 150 to 200 years, based on the International Society of Arboriculture (Lukaszkiewicz and Kosmala 2008). Some trees might be even older, but as the trunk was already split or the sprouts grew close to the original trunk, it was hard to measure the parameters of the original trunk. The allée contained few T. platyphyllos individuals, of which four were also included in our study to confirm their identity.

The individuals from Nagycenk have been divided into two groups, "Nagycenk" and "Nagycenk old individuals". This partition was done based on the trunk diameter, with the boundary between the two groups at $100 \mathrm{~cm}$. In addition, twenty-one T. cordata individuals from the Fertőd Eszterházy Castle (located $15 \mathrm{~km}$ away) were also included in our study. Trees with similar age and growth parameters stand here with allée replantation documentation dating to the very beginning of the 20th century. Hence, those trees are approx. 120 years old.

According to the trunk diameter based age estimation for both the Nagycenk and Fertőd we can state that trees with a diameter of $1 \mathrm{~m}$ or more are at least 200 years old; this age estimation refers to 20 individuals of the study ("Nagycenk old individuals"). The other 52 trees are younger, but still many are around 150 years. This is because the even younger trees have been omitted already at the sampling time.

As a control group, we used six, nowadays popular small-leaved lime cultivars within the study (five T. cordata cultivars. 'Rancho', 'Savaria', 'Roelvo', 'Greenspire', 'Winter Orange', and a Tilia hybrid 'Szent István'). Their leaves were collected in the Soroksár Experimental Field of the Hungarian University of Agriculture and Life Sciences (MATE). All leaf samples' collection happened at the end of the summer of 2018 . The leaves were stored at $-20^{\circ} \mathrm{C}$ until used.

\section{DNA extraction and fragment sizing}

DNA extraction from the frozen leaves was performed with SP Plant Mini Kit (Omega, VWR International Kft, Budapest). The DNA concentration and quality were assessed using NanoDrop (BioScience, Hungary) and visually checked on $1 \%$ agarose gel.

Nine SSR (Simple Sequence Repeat) primers (Tc963, Tc927, Tc937, Tc7, Tc31, Tc951, Tc5, Tc11, Tc915) were chosen based on the study of Phuekvilai et al. (2013). PCR was performed in $25 \mu$ l reaction volume containing 20-80 ng DNA, 10X PCR reaction buffer, $2.5 \mathrm{mM} \mathrm{MgCl}, 0.02 \mathrm{mM}$ dNTP mix, $2.5 \mu \mathrm{mol}$ of primers (forward primers were fluorescently labelled with 6-FAM), 0.5 unit of DreamTaq DNA polymerase (Fermentas, Szeged, Hungary) $1 \%$ BSA and 2\% DMSO and sterile distilled water. For the amplification of SSR fragments, the following program was used: initial denaturation at $94{ }^{\circ} \mathrm{C}$ for $5 \mathrm{~min}$; followed by 30 cycles of $94{ }^{\circ} \mathrm{C}$ for $45 \mathrm{~s}$, $50{ }^{\circ} \mathrm{C}$ for $60 \mathrm{~s}, 72{ }^{\circ} \mathrm{C}$ for $60 \mathrm{~s}$; and a final synthesis at $72{ }^{\circ} \mathrm{C}$ for $5 \mathrm{~min}$. The PCR products were applied on a $1 \%(\mathrm{w} / \mathrm{v})$ ethidium bromide-stained agarose gel in 1xTBE buffer with xylene cyanol loading buffer for verifying the amplification. The amplified SSR fragments were run on an automated sequencer ABI PRISM 3100 genetic analyser (Applied Biosystems, Budapest, Hungary). Fragment length analysis (FLA) was performed manually using Peak Scanner software 1.0 (Applied Biosystems 2006).

We used Micro-Checker (Van Oosterhout et al. 2004) to test all nine SSR loci for null alleles and possible scoring errors derived from significant allele dropout and the presence of microsatellite stutter bands.

\section{Diversity estimates}

GenAlEx v.6.5 (Peakall and Smouse 2006) was used to count the number of alleles per loci as well as to calculate the mean number of different alleles $\left(\mathrm{N}_{\mathrm{a}}\right)$ and effective alleles $\left(\mathrm{N}_{\mathrm{e}}\right)$ for each group and loci (Table 2).

Expected heterozygosity $\left(\mathrm{H}_{\mathrm{e}}\right)$, observed heterozygosity $\left(\mathrm{H}_{\mathrm{o}}\right)$, and inbreeding coefficient $\left(F_{\mathrm{IS}}\right)$ were 
calculated in R (R Core Team 2013), using the Adegenet package (Jombart and Ahmed 2011). The significance of $F_{\text {IS }}$ values was calculated separately with Hierfstat package (Goudet 2005), using 1000 permutations. Allelic richness (AR) was calculated using the Popgenreport package (Adamack and Gruber 2014). Private alleles were counted in each group using the Poppr package (Kamvar et al. 2014).

\section{Differentiation, structure and relatedness}

Genetic differentiation between groups was measured using $F_{\mathrm{ST}}$ (Nei 1973) by creating a pairwise distance matrix using the Hierfstat package and visualised as a heatmap. In addition, a UPGMA (unweighted pair group method with arithmetic mean) dendrogram was created, based on the $F_{\mathrm{ST}}$ distances, using the Ggdendro package in R (de Vries and Ripley 2013).

To infer the group structure, sub-populations and relationship among groups, a model-based Bayesian analysis was carried out as implemented in Structure 2.3.4 software (Pritchard et al. 2000). The analysis was performed with an admixture model with correlated allele frequencies. K-value (the number of genetic groups) was set to $1-10$ with a burn-in period of 100000 steps followed by 500000 repetitions of Markov chain Monte Carlo (MCMC), with 20 repetitions for each run. We applied the Evanno method (Evanno et al. 2005), as implemented in the Pophelper package (Francis 2017), to detect the value of the optimal $\mathrm{K}$ that best fit the data. The 20 simulations were averaged using CLUMPP v1.1.2 (Jakobsson and Rosenberg 2007) and represented in bar graphs using the Pophelper package.

Additionally, a Neighbor-Net network (Bryant and Moulton 2004) was constructed based on CavalliSforza and Edwards Chord distance (Dch) by CavalliSforza and Edwards (1967) and using a NeighborJoining (NJ) algorithm of Phangorn package (Schliep 2011).

We also performed a Principle Component Analysis (PCA) using the Hierfstat and FactoMineR (Lê et al. 2008) packages in $R$ to compare genetic differentiation among individuals (genotypes) and populations. Population centroids with $95 \%$ confidence ellipses derived from the PCA were plotted for each genetic cluster using Ggpubr (Kassambara and Kassambara 2020).
To assess the relationship structure within the detected age classes of the Nagycenk group (old vs young individuals), we employed the ML-Relate software (Kalinowski et al. 2006). This approach was used to determine whether the old individuals were related to the younger trees, similarly to Ikeda et al. (2019). First, we calculated the pairwise relatedness coefficient using a maximum likelihood approach for all individuals ( $r$, the fraction of alleles identical by descent shared by individuals; Blouin 2003). Then, we compared the ratio of the detected pedigree relationships (unrelated (U), half-siblings (HS), full-siblings (FS), and parent-offspring (PO)) and the mean $r$ coefficient between the groups of individuals. Descriptive statistics were calculated in $\mathrm{R}$ using the Dply package (Wickham 2014). To compare the ratio of related individuals between the groups, a two-sample test for equality of proportions (two-proportions Z-test) was carried out using the Stats package v 4.2.0 (R Core Team 2013). Before comparing group means, to test whether distributions of variables met normality requirements, we applied Shapiro-Wilk normality tests implemented in Stats. Mean $r$ coefficients were compared using the two-sample (independent) Wilcoxon rank-sum test. Throughout the analysis, 95\% confidence intervals (CI) were applied.

\section{Results}

Amplification was successful with all nine SSR markers. However, primers for the Tc7 locus amplified four alleles in most samples, suggesting the marker to be multilocus, so we omitted these data from the final evaluation. Micro-Checker test confirmed the lack of null alleles, and all SSR loci conformed to HWE, showing no significant deviation from it.

The number of alleles per locus ranged from 4 (Tc951, Tc31, Tc927) to 18 (Tc963) in the samples of Nagycenk, including the old individuals (Table 1). In the Fertôd samples, the number of alleles ranged from 3 (Tc31) to 12 (Tc915), and in the case of the six cultivars from $2(\mathrm{Tc} 31)$ to 6 (Tc951). The mean number of different alleles $\left(\mathrm{N}_{\mathrm{a}}\right)$ and effective alleles $\left(\mathrm{N}_{\mathrm{e}}\right)$ indicated that the largest polymorphism was present at the Tc963, Tc915 and Tc5 loci (Table 2). The eight primer pairs produced a total of 108 alleles. The amplified alleles' sizes were around the expected size 
Table 1 The number of the amplified alleles, different alleles and effective alleles at the studied SSR loci by study groups

$N_{a}$ mean no. of Different Alleles; $N_{e}$ mean no. of Effective Alleles

\begin{tabular}{lllllrl}
\hline Locus & $\begin{array}{l}\text { Nagycenk old } \\
\text { ind. N=20 }\end{array}$ & $\begin{array}{l}\text { Nagycenk } \\
\mathrm{N}=52\end{array}$ & $\begin{array}{l}\text { Cultivars } \\
\mathrm{N}=6\end{array}$ & Fertőd N=21 & $\mathrm{N}_{\mathrm{a}}$ & $\mathrm{N}_{\mathrm{e}}$ \\
\hline Tc963 & 12 & 18 & 5 & 8 & 10.750 & 3.227 \\
Tc927 & 4 & 10 & 2 & 5 & 5.250 & 1.618 \\
Tc937 & 7 & 10 & 3 & 5 & 6.250 & 1.948 \\
Tc31 & 4 & 9 & 2 & 3 & 4.500 & 1.495 \\
Tc951 & 4 & 5 & 6 & 4 & 4.750 & 3.053 \\
Tc5 & 9 & 11 & 4 & 8 & 8.000 & 4.492 \\
Tc11 & 6 & 10 & 3 & 5 & 6.000 & 2.921 \\
Tc915 & 11 & 16 & 5 & 12 & 11.000 & 5.459 \\
\hline
\end{tabular}

\begin{tabular}{llllll}
\hline Locus & Expected size & Nagycenk old ind & Nagycenk & Cultivars & Fertőd \\
\hline Tc963 & 238 & $231-277$ & $229-275$ & $236-262$ & $236-280$ \\
Tc927 & 157 & $135-163$ & $135-160$ & $143-149$ & $143-160$ \\
Tc937 & 162 & $148-168$ & $142-166$ & $148-158$ & $150-194$ \\
Tc31 & 205 & $192-213$ & $192-211$ & $194-196$ & $194-202$ \\
Tc951 & 160 & $156-162$ & $156-164$ & $148-162$ & $156-162$ \\
Tc5 & 150 & $139-176$ & $139-176$ & $139-158$ & $139-164$ \\
Tc11 & 146 & $116-147$ & $124-149$ & $124-133$ & $130-149$ \\
Tc915 & 165 & $148-190$ & $148-178$ & $152-172$ & $148-180$ \\
\hline
\end{tabular}

Table 2 The observed size of the amplified alleles (in base pairs) in studied SSR loci by study groups compared to Phuekvilai et al. (2013)
(Table 2) based on published data (Phuekvilai et al. 2013).

Diversity parameters are given in Table 3. Samples from Nagycenk, including the old individuals, showed the highest observed and expected heterozygosity (mean $\mathrm{H}_{\mathrm{o}}=0.694, \mathrm{H}_{\mathrm{e}}=0.612$ ) and the highest number of allelic richness (mean $\mathrm{AR}=4.254$ ). The number of private alleles (group-specific; mean $\mathrm{N}_{0}=18.5$ ) was over 3-times and 6-times higher compared to Fertôd $\left(\mathrm{N}_{\mathrm{p}}=5\right)$ and the control cultivars $\left(\mathrm{N}_{\mathrm{p}}=3\right)$. The Fertôd group presented slightly lower diversity $\left(\mathrm{H}_{\mathrm{o}}=0.624, \mathrm{H}_{\mathrm{e}}=0.596, \mathrm{AR}=3.943\right)$ compared to Nagycenk's. As expected, the investigated control Tilia cultivars showed the least diversity
$\left(\mathrm{H}_{\mathrm{o}}=0.625, \quad \mathrm{H}_{\mathrm{e}}=0.515, \quad \mathrm{AR}=3.339\right) . \quad$ Inbreeding coefficients were consistently negative among all groupss (mean $F_{\mathrm{IS}}=-0.081$ ), and none of them was significant at the $p<0.05$ level.

Nei's pairwise $F_{\mathrm{ST}}$ values imply only a slight (0.007-0.06) differentiation among groups. The $F_{\mathrm{ST}}$ value of the samples from Nagycenk compared to the old individuals of Nagycenk was almost zero showing shallow genetic differentiation (Fig. 1). The $F_{\mathrm{ST}}$ value of the Nagycenk samples compared to the Fertőd samples' value shows very little $(0.023-0.027)$ differentiation. The highest $F_{\mathrm{ST}}$ value was found between the cultivars and the Nagycenk group, although it was very low (0.06). Accordingly,
Table 3 Genetic diversity estimation for the studied four populations

$N$ sample size; $H o$ observed heterozygosity, $\mathrm{He}$ expected heterozygosity; $A R$ mean allelic richness; $N p$ number of private alleles; $F_{I S}$ inbreeding coefficient; $n s$ non-significant $(p<0.05)$

\begin{tabular}{lllllll}
\hline Population & $\mathrm{N}$ & $\mathrm{H}_{\mathrm{o}}$ & $\mathrm{H}_{\mathrm{e}}$ & $\mathrm{AR}$ & $\mathrm{N}_{\mathrm{p}}$ & $F_{\text {IS }}$ \\
\hline Nagycenk & 52 & 0.651 & 0.595 & 4.311 & 31 & $-0.066^{\mathrm{ns}}$ \\
Nagycenk old ind & 20 & 0.737 & 0.630 & 4.197 & 6 & $-0.144^{\mathrm{ns}}$ \\
Mean & & 0.694 & 0.612 & 4.254 & 18.5 & -0.105 \\
Fertőd & 21 & 0.624 & 0.596 & 3.943 & 5 & $-0.044^{\mathrm{ns}}$ \\
cultivars & 6 & 0.625 & 0.515 & 3.339 & 3 & $-0.070^{\mathrm{ns}}$ \\
Mean & & 0.659 & 0.584 & 3.947 & 11.25 & -0.081 \\
\hline
\end{tabular}




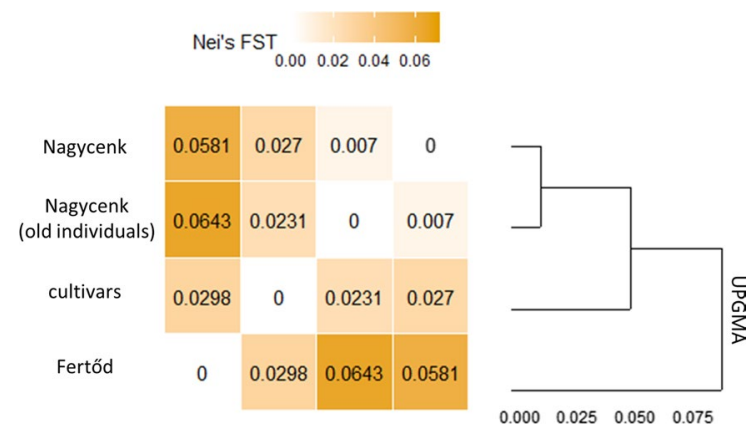

Fig. 1 Heatmap of Nei's pairwise $F_{S T}$ calculated between all pairs of populations (Nei 1987). Darker colors indicate stronger differentiation. The UPGMA dendrogram, showing the genetic relatedness between populations, is based on the pairwise $F_{S T}$ values the UPGMA dendrogram of $F_{\mathrm{ST}}$ showed the closest relationship (shortest genetic distance) between the Nagycenk group and the cultivars and Fertőd as separate branches with higher distances.

Bayesian Structure analysis clearly distinguished the samples of Nagycenk from Fertőd (Fig. 2a). The Evanno method indicated that a $\mathrm{K}=3$ model fits best the data (Fig. 2b). The Nagycenk individuals (including both the old and younger individuals) form one cluster; another cluster is the Fertôd individuals and the cultivars (with high admixture); the third cluster is formed by four Nagycenk individuals, all identified as T. plathphyllos. The neighbour-net network of genetic clusters showed high similarities among the Nagycenk group (0.0358-0.0481), based on their evolutionary distance estimated with a neighbour-joining

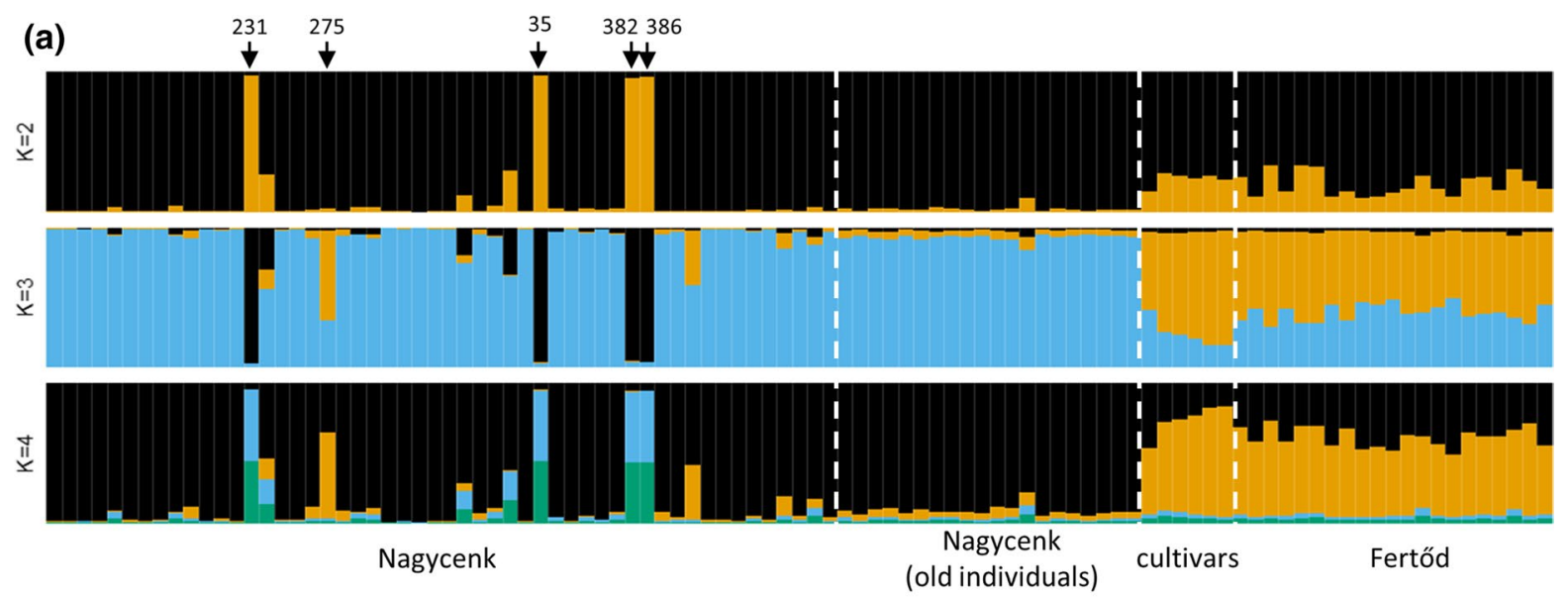

(c)

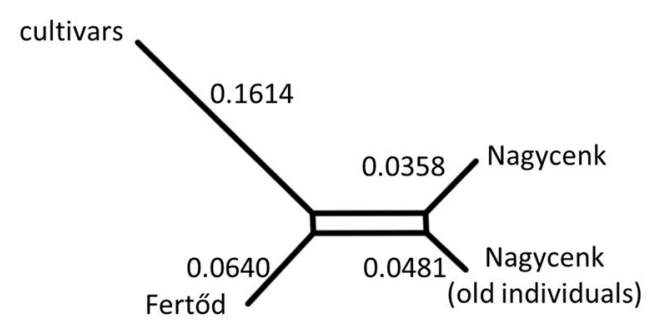

(b)

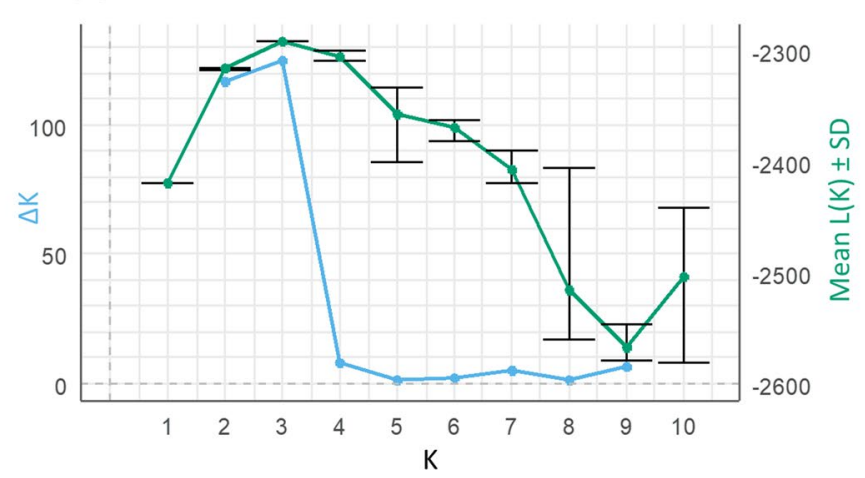

ing to the method of Evanno et al. (2005). b Neighbor-net network of genetic clusters (Bryant and Moulton 2004). Edge values correspond to the distance of each cluster estimated
Fig. 2 a Bayesian estimation of population structure in 99 individuals of Tilia cordata at $\mathrm{K}=2,3$ and 4 as determined by STRUCTURE (Pritchard et al. 2000). The most likely number of clusters is defined by Mean $\mathrm{L}(\mathrm{K})$ and delta $\mathrm{K}$ values accord- 
method and increasing distances for Fertőd (0.0640) and the control cultivars (0.1614) (Fig. 2c).

The Principal Component Analysis (PCA) of the Nagycenk group, Fertôd and the control cultivars widely scattered all 99 individuals (Fig. 3a). The first two axes (PC1 and PC2) explained only $21.97 \%$ of the total variance, while the other two axes (PC3 and PC4) even less, $6.78 \%$ and $6.11 \%$. Around the group centroids, confidence ellipses were partly overlapping, but the Nagycenk and Fertőd clearly separated. Similarly to the Structure analysis, few individuals (e.g. 231, 382, 35, and 386) sharply separated from all groups (Fig. 3a). These were the same individuals which formed the third cluster in the Structure analysis, the four T. platyphyllos trees. The joint grouping of young and old individuals of Nagycenk was evident when PC3 and PC4 axes were considered (Fig. 3b).

Both age groups presented high number of unrelated individuals (Nagycenk old ind. $U=143$; young ind. $U=1047$ ), this was about 10-times higher than any types of relationship detected (Nagycenk old ind. $\mathrm{PO}=9, \mathrm{HS}=26, \mathrm{FS}=12$; young ind. $\mathrm{PO}=52$, $\mathrm{HS}=146, \mathrm{FS}=54)$. The value of relatedness $(r)$ ranged from 0.00 to 0.82 with a mean of 0.115 in Nagycenk old ind. (sd: 0.163 ) and 0.081 in the young ind. group (sd: 0.141). The comparison of estimated relatedness between the age groups using Z-test ( $p$ value $=0.0817$ ), as well as the comparison of mean $r$ coefficients using Wilcoxon rank-sum test, resulted in non-significant difference $(p$ value $=0.0784)$ at the $p<0.05$ level (Fig. 4).

\section{Discussion}

The assessment of genetic diversity is a critical factor for ecosystem management and conservation of genetic material for population viability. This work aimed to assess the genetic diversity, differentiation and structure of the late-Baroque lime tree allee of Nagycenk.

Phuekvilai and Wolff (2013) published 15 SSR primers pairs, of which we have used eight pairs in course of our work, which produced the highest number of alleles. Even though these markers were developed for T. platyphyllos, their successful transferability to $T$. cordata has been proven by the cited authors; our study also confirmed the statement. Logan et al. (2015) have used these markers to discriminate between $T$. cordata and $T$. platyphyllos and their hybrid, T. $\times$ europaea, to assess the population genetic
Fig. 3 a Principal component analysis (PCA) of populations from Nagycenk, Fertôd and the control cultivars genotyped in this study. X-axis denotes the value of $\mathrm{PC} 1$, while $y$-axis denotes the value of $\mathrm{PC} 2$, with each dot in the figure representing one individual. The color for individuals corresponds to the population classification. b PCA plots of axes PC2-PC3 and PC3-PC4 explaining less variance in the data. Confidence ellipses $(P=0.95)$ around population centroids are marked with a solid line

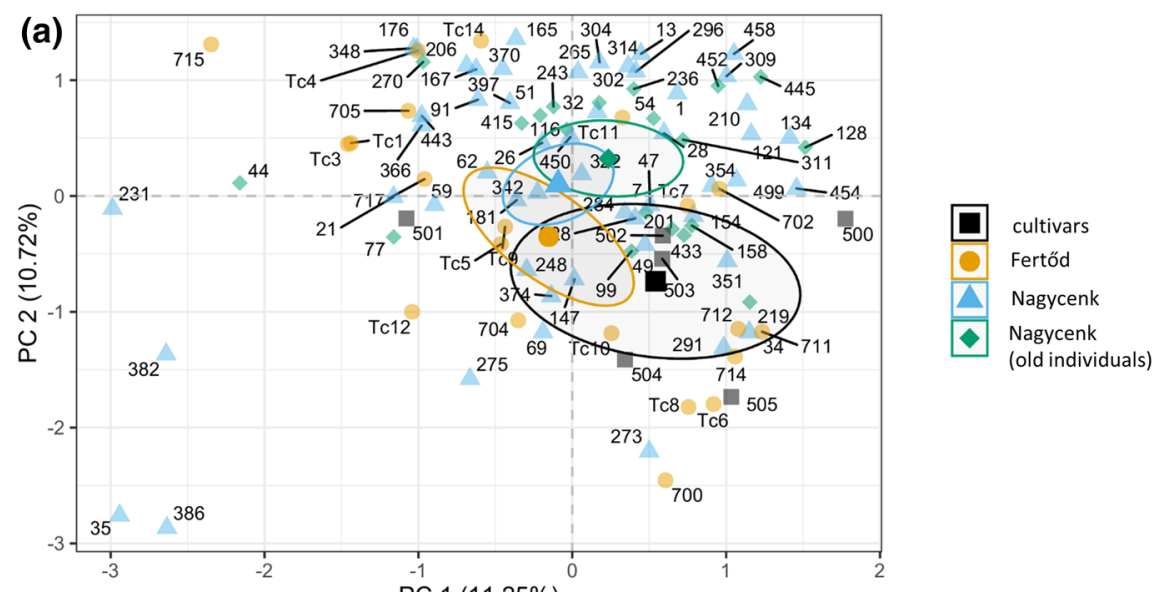

(b)
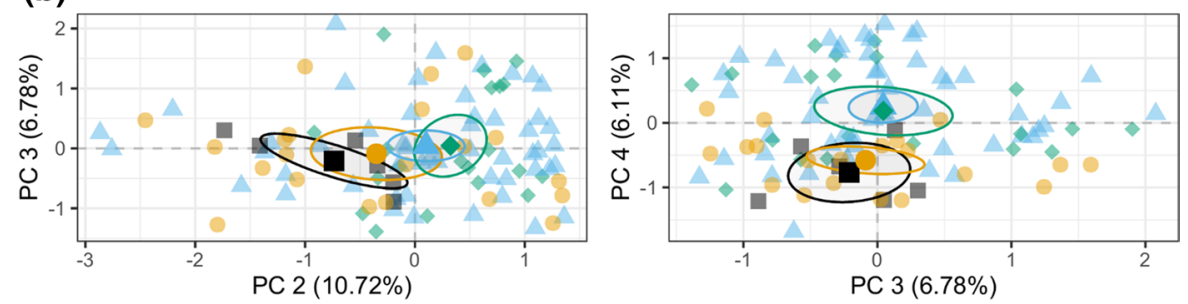
(a)

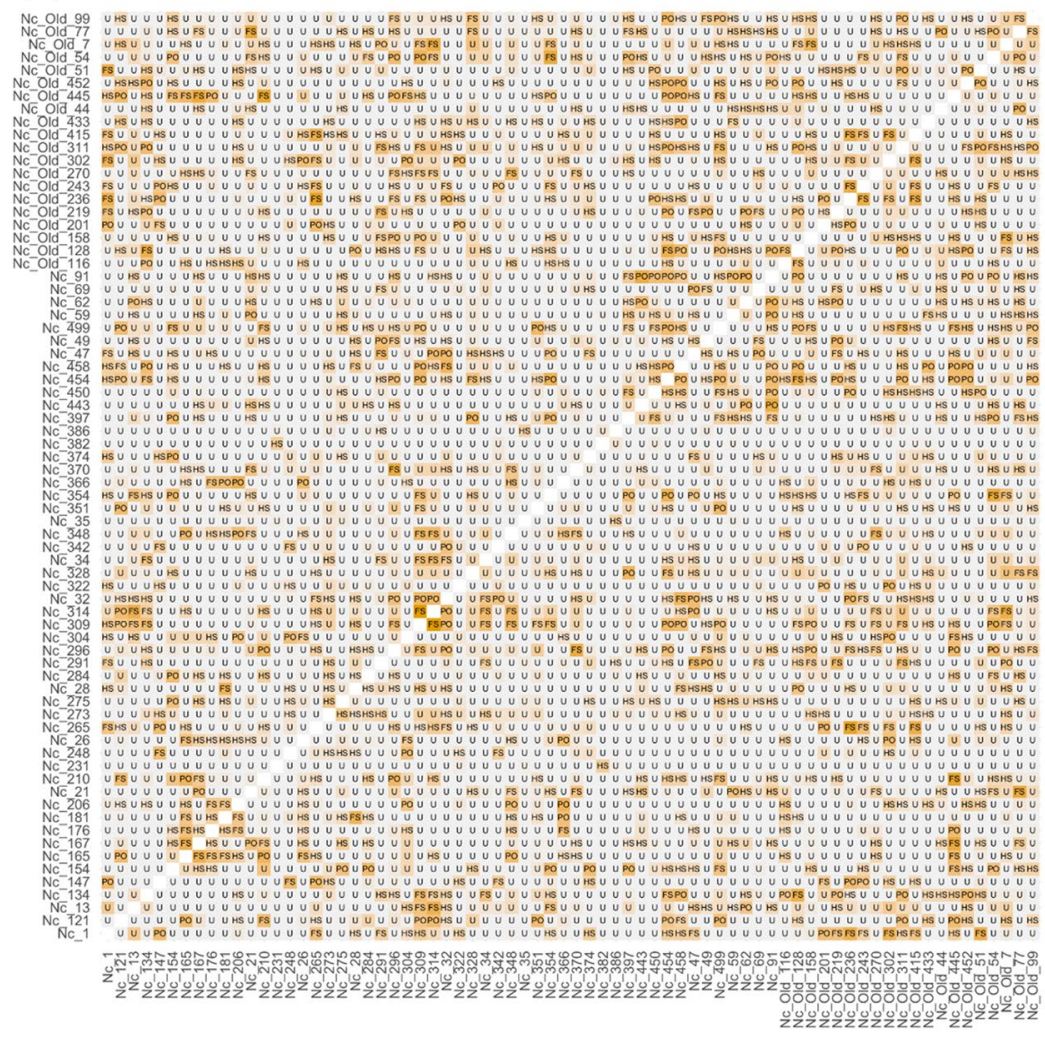

Relatedness (b)

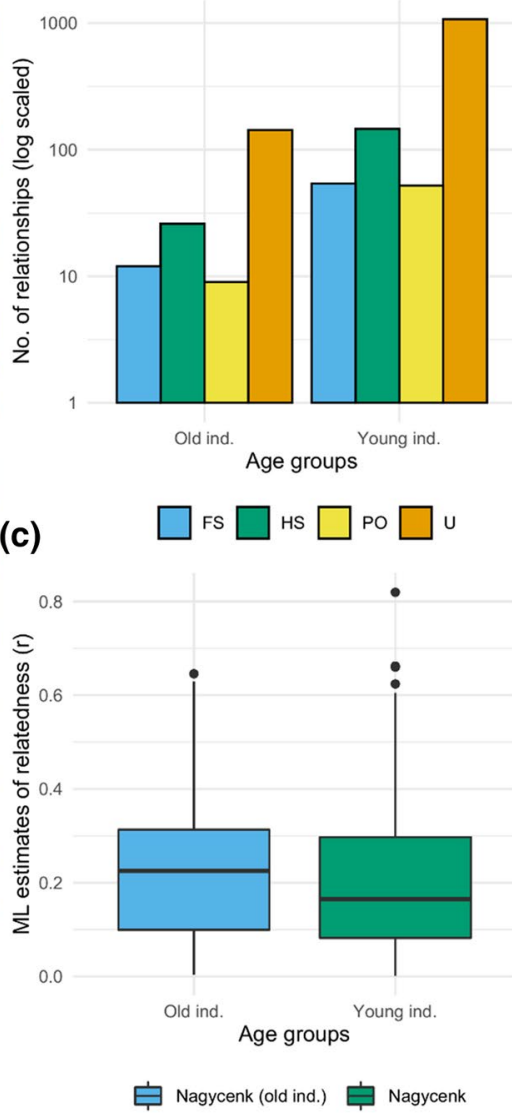

Fig. 4 a Maximum Likelihood estimate of individual relatedness ( $r$ coefficients) and the determined relationships (unrelated (U), half-siblings (HS), full-siblings (FS), and parentoffspring (PO)) among the individuals of Nagycenk using

diversity of the two species in the UK. They reported high variability and could distinguish between pure species and hybrids using Bayesian clustering and ordination techniques. We identified few $T$. platyphyllos individuals $(231,382,35$ and 386) in the Nagycenk group already at the time of sampling. Identification of $T$. cordata is rather easy based on the leaves, which are hairless on both sides except for the small groups of brown hair in the leaf vein axils. In contrast T. platyphyllos and T. $x$ europaea both have white hair on the underside of the leaves, but while the leaves of $T$. platyphyllos are covered with downy white hair fully, the leaves of T. $x$ europaea has the white hair only in the leaf vein axils. Our morphological observation and the revealed SSR alleles confirm that these individuals belong to the T. platyphyllos
ML-relate (Kalinowski et al. 2006). b Comparison of age groups by the type of relationship determined (Z-test). c Comparison of $r$ coefficients between the age groups (Wilcoxon rank sum test)

species. During allele counting and discrimination, specific alleles were observed for these individuals. Additionally, samples were well separated and positioned at the periphery on the PCA plot (PC1 vs PC2), and the four samples clustered separately (K2 - K4) during the Structure analysis (Figs. 2 and 3).

The Nagycenk allée (and the Fertôd allée) can be regarded as an artificial population. The genetic diversity was in the same magnitude as in the study of Logan et al. (2015) with natural UK populations. However, in that study more SSR loci have been used, of which we only studied the most diverse one. Detected allele numbers by loci are approximately the same; in loci Tc927 and Tc937, even more alleles (Tc927: 4 by Logan and 10 by us, Tc937: 6 by Logan 10 by us) were detected in our study. Similarly, high 
levels of genetic diversity, expected and observed heterozygousity, were revealed in our survey for our populations (e.g. Nagycenk mean $\mathrm{H}_{\mathrm{e}}$ : 0.694 and $\mathrm{H}_{\mathrm{o}}$ : 0.612). However, contrary, Phuekvilai (2014) studied a wild modern-day population from Hungary (HUOL, Oltárc, Hungary; $\left.\mathrm{H}_{\mathrm{e}}: 0.538, \mathrm{H}_{\mathrm{o}}: 0.508\right)$, and Logan et al. (2019) four populations from Austria (AUDO, AUSO, AUST, AUTH; $\mathrm{H}_{\mathrm{e}}: 0.588, \mathrm{H}_{\mathrm{o}}: 0.573$ ) and both studies detected much lower genetic diversity. It is possible that our individuals, especially the old trees $\left(\mathrm{H}_{\mathrm{e}}: 0.737\right.$ and $\left.\mathrm{H}_{\mathrm{o}}: 0.630\right)$, estimated to be approximately 200 years old, could preserve the diversity of the former natural populations of the region. An example is the $T$. cordata remnants of ancient forests in Denmark, where similar diversity was measured $\left(\mathrm{H}_{\mathrm{e}}: 0.62\right.$ and $\left.\mathrm{H}_{\mathrm{o}}: 0.62\right)$ (Erichsen et al. 2019). Also, in the study of Lobo et al. (2018), comparable diversity was detected $\left(\mathrm{H}_{\mathrm{e}}: 0.625\right.$ and $\mathrm{H}_{\mathrm{o}}$ : 0.632$)$, where trees were sampled from small isolated relict populations preserved in the framework of the "Danish genetic resource conservation program" (Graudal et al. 1995). An alternative hypothesis would be that our populations in Central Europe could be genetically more diverse due to the meeting of several post-glacial migration routes (Phuekvilai 2014; Semerikova et al. 2020). Tilia species could retain high genetic diversity for a long time due to their high abundance during warmer periods, outcrossing mating system and increased longevity (Myking 2002; Wolff et al. 2021). However, this would require extensive sampling of the native populations of the geographic region.

In addition, our diversity estimation supports the hypothesis of Gerzson and Szilágyi (2011), according to which the late Baroque allée's plantation was done by collecting sprouts or seedlings in the neighbouring forests. Vanden Broeck et al. (2018) compared the genotypic diversity of historical plantings of $T$. $\times$ europaea from the 17 th century with the genotypic diversity of currently available planting stock in Belgium and the Netherlands. Despite that, she found mainly two clones ('Pallida' and 'Zwarte linde') among the investigated trees; the genetic diversity of the historical plantings was about 4-times higher than in the current commercial planting stocks. Wolff et al. (2019) as well as Vanden Broeck et al. (2018) confirmed the theory of Hansen et al. (2014) that the same clones have been produced for decades/ centuries by private nurseries in the Netherlands and
Germany. Since neither uniform allele frequencies nor similar allele distributions were observed in our dataset during the statistical analysis, it is unlikely that the studied trees would have been clonally propagated.

None of the studied groups showed signs of inbreeding, and all $F_{\text {IS }}$ values were negative (mean $F_{\text {IS }}$ : -0.081 ). Thus, even though small populations are more vulnerable to inbreeding (Ellstrand and Elam 1993), our value indicates that groups experience gene flow (heterozygote excess) and/or did not develop inbreeding in the original population where the propagation material came from. In addition, Tilia species are known for being highly outcrossing, with inbreeding coefficients $\left(F_{\text {IS }}\right.$ ) close to zero (Wolff et al. 2021).

The lack of substantial genetic differentiation detected between the young and old individuals of Nagycenk is not unexpected. Both the Structure and the Neighbor-Net network analyses tightly linked these groups, with low genetic differentiation between them. Presumably, either the younger individuals originated from the same seed source, or they can be relatives of the old individuals; however, this latter is unlikely since our relatedness analysis and the comparison of $r$ coefficients reject this assumption. Most possibly, both age groups origins from the same seed source but at a different time.

The sharp separation of the Nagycenk samples from the Fertôd group might be the consequence that plant material used during the reestablishment of the park in the early 1900s (Szilágyi and Szabó, 2020) was of native but non-local origin. Allochthonous populations, which could hybridise with local populations, were frequently planted in this period (Pâques 2013). Tilia species and cultivars, e.g. Tilia tomentosa 'Petiolaris', were already planted in the 1700s in Hungary (Pigott 2012). In addition, it should be mentioned, that János Wagner, the prominent Hungarian botanist (1870-1975, Austria-Hungary) obtained his systematical Tilia collection from Fertőd. As Vöröss (1984) describes this collection, "Most of the specimens, both as regards numbers and number of forms, came from Eszterháza (=Fertód), from the famous park of the ESTERHÁZYs. This aristocratic family must have liked lindens, as there are great numbers of varieties in their park'. Thus, we cannot rule out the possibility that the trees of Fertőd were collected or purchased from elsewhere, from a non-local seed 
source. According to the land-use system of the Esterházy garden complex, a tree nursery used to be a vital functional part for centuries, where seedling collection or purchase either from local or remote regions created the basic plant stock.

Similarly to Fertőd, the examined six cultivars showed low genetic differentiation and separation from Nagycenk. Neither the Structure nor the PCA analyses were unable to discriminate these individuals. Expectedly, during the diversity estimation, we found minor private alleles and allelic richness. This finding indicates that our markers are not sufficient to detect a genetic pattern specific to the cultivars.

\section{Conclusion}

The use of a restricted number of cultivars and clones may pose a risk to global biodiversity, especially in today's rapidly changing world. Our study is the first to explore the genetic composition of small-leaved lime trees growing in a Hungarian historic garden. The trees of Nagycenk preserved substantial amounts of genetic variation, presenting shallow differentiation, lack of inbreeding and genetic erosion due to their seed source origin and high longevity. This collection, despite being artificial, potentially resembles the former genetic diversity of native local lime tree populations. The old trees have shown long-term disease resistance hence could provide valuable genetic material for breeders. Genetic conservation and recurrent selection from such collections, and from where these trees originate, would be an efficient way of maintaining the genetic diversity. For these reasons, assessing the genetic heritage of the late-Baroque historic garden of Nagycenk is essential. As the renewal of the Nagycenk allée is timely, these results can help to decide the strategy to be used. The allée represents a broad genetic base for the species, which is definitely worth preserving.

Author contributions KSZ, EGyT and ZsGy devised the project, EGyT and ZsGy formulated the main conceptual ideas and proof outline. AP and ZsGy collected the plant material and performed the laboratory analyses. EGyT and ZsGy performed the statistical analysis of genetic data. EGyT and ZsGy wrote the manuscript. KSz provided suggestions for data analyses and feedback and editing on the manuscript drafts.
Funding Open access funding provided by Hungarian University of Agriculture and Life Sciences. This research was supported by the Ministry for Innovation and Technology within the framework of the Thematic Excellence Programme 2020- Institutional Excellence Subprogram (TKP2020IKA-12) for research on plant breeding and plant protection and was partly privately funded by GyZs and EGyT.

Data availability The datasets generated and analyzed during the current study are available from the authors.

\section{Declarations}

Conflict of interest The authors declare that they have no known competing financial interests or personal relationships that could have appeared to influence the work reported in this paper.

Open Access This article is licensed under a Creative Commons Attribution 4.0 International License, which permits use, sharing, adaptation, distribution and reproduction in any medium or format, as long as you give appropriate credit to the original author(s) and the source, provide a link to the Creative Commons licence, and indicate if changes were made. The images or other third party material in this article are included in the article's Creative Commons licence, unless indicated otherwise in a credit line to the material. If material is not included in the article's Creative Commons licence and your intended use is not permitted by statutory regulation or exceeds the permitted use, you will need to obtain permission directly from the copyright holder. To view a copy of this licence, visit http://creativecommons.org/licenses/by/4.0/.

\section{References}

Adamack AT, Gruber B (2014) PopGenReport: simplifying basic population genetic analyses in R. Methods Ecol Evol 5:384-387. https://doi.org/10.1111/2041-210x.12158

Blouin MS (2003) DNA-based methods for pedigree reconstruction and kinship analysis in natural populations. Trends Ecol Evol 18:503-511. https://doi.org/10.1016/ s0169-5347(03)00225-8

Bryant D, Moulton V (2004) Neighbour-net: an agglomerative method for the construction of phylogenetic networks. Mol Biol Evol 21:255-265. https://doi.org/10.1093/molbev/msh018

Cavalli-Sforza LL, Edwards AW (1967) Phylogenetic analysis. Models and estimation procedures. Am J Human Genet 19:233. https://doi.org/10.2307/2406616

Ciaffi M, Alicandri E, Vettraino AM, Paolacci AR, Tamantini M, Tomao A, Agrimi M, Kuzminsky E (2018) Conservation of veteran trees within historical gardens (COVE): a case study applied to Platanus orientalis L. in central Italy. Urb For Urb Green 34:336-347. https://doi.org/10. 1016/j.ufug.2018.07.022

De Jaegere T, Hein S, Claessens H (2016) A review of the characteristics of small-leaved lime (Tilia cordata Mill.) 
and their implications for silviculture in a changing climate. Forests 7:56. https://doi.org/10.3390/f7030056

de Vries A, Ripley BD (2013) Ggdendro: tools for extracting dendrogram and tree diagram plot data for use with ggplot. R package version 0.1-12. https://cran.r-proje ct.org/web/packages/ggdendro/vignettes/ggdendro.html (Accessed: July 20, 2021)

Eaton E, Caudullo G, de Rigo D (2016) Tilia cordata, Tilia platyphyllos and other limes in Europe: distribution, habitat, usage and threats. In: San-Miguel-Ayanz J, de Rigo D, Caudullo G, Houston Durrant T, Mauri A (Eds.) European Atlas of Forest Tree Species. Publ. Off. EU, Luxembourg, pp. e010ec5+ https://doi.org/10.2788/4251

Edwards CE, Jackson PW (2019) The development of plant conservation in botanic gardens and the current and future role of conservation genetics for enhancing those conservation efforts. Mol Front J 3:44-65. https://doi.org/10. $1142 / \mathrm{s} 2529732519400078$

Ellstrand NC, Elam DR (1993) Population genetic consequences of small population size: implications for plant conservation. Annu Rev Ecol Syst 24:217-242. https:// doi.org/10.1146/annurev.es.24.110193.001245

Erichsen EO, Wolff K, Hansen OK (2019) Genetic and clonal structures of the tree species Tilia cordata Mill. in remnants of ancient forests in Denmark. Popul Ecol 61:243255. https://doi.org/10.1002/1438-390x.12002

Evanno G, Regnaut S, Goudet J (2005) Detecting the number of clusters of individuals using the software STRUCTU RE: a simulation study. Mol Ecol 14:2611-2620. https:// doi.org/10.1111/j.1365-294x.2005.02553.x

Fineschi S, Salvini D, Taurchini D, Carnevale S, Vendramin GG (2003) Chloroplast DNA variation of Tilia cordata (Tiliaceae). Can J For Res 33:2503-2508. https://doi.org/ 10.1139/x03-179

Francis RM (2017) Pophelper: an R package and web app to analyse and visualize population structure. Mol Ecol Resour 17:27-32. https://doi.org/10.1111/1755-0998. 12509

Frankham R (2005) Genetics and extinction. Biol Cons 126:131-140. https://doi.org/10.1016/j.biocon.2005.05. 002

Frankham R, Ralls K (1998) Inbreeding leads to extinction. Nature 392:441-442. https://doi.org/10.1038/33022

Fromm M, Hattemer HH (2003) Inheritance of allozymes and hybridization in two European Tilia species. Heredity 91:337-344. https://doi.org/10.1038/sj.hdy.6800325

Gerzson L, Szilágyi K (2011) Thoughts on the condition of the lime-tree avenue in Nagycenk and the possibilities for its renewal. 4D J Landsc Archit Garden Art 21:2-20

Gerzson L, Bede Fazekas Á, Szilágyi K (2012) The long term preservation of an 18th century gene bank heritage case study of the Széchenyis' lime tree allée at Nagycenk. Appl Ecol Environ Res 10(1):44-64. https://doi.org/10.15666/ aeer/1001_04706

Goudet J (2005) Hierfstat, a package for R to compute and test hierarchical F-statistics. Mol Ecol Notes 5:184-186. https://doi.org/10.1111/j.1471-8286.2004.00828.x

Graudal L, Kjær ED, Canger S (1995) A systematic approach to the conservation of genetic resources of trees and shrubs in Denmark. For Ecol Manage 73:117-134. https:// doi.org/10.1016/0378-1127(94)03497-k
Hansen OK, Thomsen P, Rasmussen CW (2014) DNA markers provide insight about common lime in historical plantings - an example from the royal danish gardens. Urb For Urb Green 13:543-552. https://doi.org/10.1016/j.ufug. 2014.04.001

Harlov-Csortán M (2017) From the borderland of the iron curtain to european and world cultural heritage. Folk: Electron J Folk 70:193-224. https://doi.org/10.7592/fejf2017. 70.harlov_csortan

Hosseinzadeh Colagar A, Yusefi M, Zarei M, Yousefzadeh H (2013) Assessment of genetic diversity of Tilia rubra DC. by RAPD analysis in the Hyrcanian forests, north of Iran. Pol J Ecol 61:341-348

Ikeda T, Mishima K, Takata K, Tomaru N (2019) The origin and genetic variability of vegetatively propagated clones identified from old planted trees and plantations of Thujopsis dolabrata var. hondae in Ishikawa Prefecture, Japan. Tree Genet Genomes 15:1-12. https://doi.org/10. 1007/s11295-019-1391-0

Jakobsson M, Rosenberg NA (2007) CLUMPP: a cluster matching and permutation program for dealing with label switching and multimodality in analysis of population structure. Bioinformatics 23:1801-1806. https:// doi.org/10.1093/bioinformatics/btm233

Jombart T, Ahmed I (2011) adegenet 1.3-1: new tools for the analysis of genome-wide SNP data. Bioinformatics 27:3070-3071. https://doi.org/10.1093/bioinformatics/ btr521

Kalinowski ST, Wagner AP, Taper ML (2006) ML-Relate: a computer program for maximum likelihood estimation of relatedness and relationship. Mol Ecol Notes 6:576579. https://doi.org/10.1111/j.1471-8286.2006.01256.x

Kamvar ZN, Tabima JF, Grünwald NJ (2014) Poppr: an R package for genetic analysis of populations with clonal, partially clonal, and/or sexual reproduction. PeerJ 2:e281. https://doi.org/10.7717/peerj.281

Kassambara A, Kassambara MA (2020) Package 'ggpubr'. https://github.com/kassambara/ggpubr

Lê S, Josse J, Husson F (2008) FactoMineR: an R package for multivariate analysis. J Stat Soft 25:1-18. https://doi. org/10.18637/jss.v025.i01

Liesebach H, Sinko Z (2008) A contribution to the systematics of the genus Tilia with respect to some hybrids by RAPD analysis. Dendrobiology 59:13-22

Lobo A, Hansen OK, Hansen JK, Erichsen EO, Jacobsen B, Kjær ED (2018) Local adaptation through genetic differentiation in highly fragmented Tilia cordata populations. Ecol Evol 8:5968-5976. https://doi.org/10.1002/ ece 3.4131

Logan SA, Phuekvilai P, Wolff K (2015) Ancient woodlands in the limelight: delineation and genetic structure of ancient woodland species Tilia cordata and Tilia platyphyllos (Tiliaceae) in the UK. Tree Genet Genomes 11:52. https://doi.org/10.1007/s11295-015-0872-z

Logan SA, Phuekvilai P, Sanderson R, Wolff K (2019) Reproductive and population genetic characteristics of leading-edge and central populations of two temperate forest tree species and implications for range expansion. For Ecol Manage 433:475-486. https://doi.org/10. 1016/j.foreco.2018.11.024 
Lukaszkiewicz J, Kosmala M (2008) Determining the age of streetside trees with diameter at breast height-based multifactorial model. Arboric Urb For 34:137-143

Miller RW (2004) Urban forestry: history and introduction forestry serving urbanised societies. IUFRO World Series 14:17-23

Myking T (2002) Evaluating genetic resources of forest trees by means of life-history traits-a Norwegian example. Biodivers Conserv 11:1681-1696. https://doi.org/10. 1023/a:1016814817208

Mylett AJ (2015) Genetic diversity and regenerative potential of Tilia cordata Miller in the Lincolnshire Limewoods. $\mathrm{PhD}$ thesis, University of Lincoln, Great Britain

Nei M (1973) Analysis of gene diversity in subdivided populations. Proc Natl Acad Sci 70:3321-3323. https://doi. org/10.1073/pnas.70.12.3321

Nei M (1987) Molecular evolutionary genetics. Columbia University Press, New York. https://doi.org/10.7312/ nei-92038

Pâques LE (2013) Forest tree breeding in Europe. Current state-of-the-art and perspectives. Springer, Netherlands, Dordrecht. https://doi.org/10.1007/978-94-007-6146-9

Peakall R, Smouse PE (2006) GenAlEx 6: genetic analysis in Excel. Population genetic software for teaching and research. Mol Ecol Notes 6:288-295. https://doi.org/10. 1111/j.1471-8286.2005.01155.x

Phuekvilai P, Wolff K (2013) Characterization of microsatellite loci in Tilia Platyphyllos (Malvaceae) and cross-amplification in related species. Appl Plant Sci 1:1200386. https://doi.org/10.3732/apps.1200386

Phuekvilai P (2014) Relicts, Refugia and Reticulation: A study of population history, hybrids and phylogeny in the longlived flowering tree genus Tilia. PhD thesis, Newcastle University, Great Britain

Pigott CD (1989) Factors controlling the distribution of Tilia cordata Mill. at the northern limits of its geographical range. IV. Estimated ages of the trees. New Phytol 112:117-121. https://doi.org/10.1111/j.1469-8137.1989. tb00316.x

Pigott D (2012) Lime-trees and Basswoods: A Biological Monograph of the Genus Tilia, 1st edn. Cambridge University Press, New York, NY, USA, p 69

Potter KM, Jetton RM, Bower A, Jacobs DF, Man G, Hipkins VD, Westwood M (2017) Banking on the future: progress, challenges and opportunities for the genetic conservation of forest trees. New Forest 48:153-180. https://doi.org/10. 1007/s11056-017-9582-8

Pritchard JK, Stephens M, Donnelly P (2000) Inference of population structure using multilocus genotype data. Genetics 155:945-959. https://doi.org/10.1093/genetics/155.2.945

R Core Team (2013) R: A language and environment for statistical computing. R Foundation for Statistical Computing, Vienna
Schliep KP (2011) phangorn: phylogenetic analysis in R. Bioinformatics 27:592-593. https://doi.org/10.1093/bioin formatics/btq706

Semerikova SA, Isakov IY, Semerikov VL (2020) Chloroplast DNA variation shed light on the history of lime tree (Tilia cordata sl) in the eastern part of the range. Russ J Genet 56:192-203. https://doi.org/10.1134/s1022795420020118

Szilágyi K, Szabó K (2020) Eszterháza központi kertjeinek faállomány vizsgálata és a barokk fasorok megújítása (Assessment of the wood stock in the central gardens of Eszterháza and the renewal of the baroque tree lines). Eszterháza kertmúvészete fehéren feketén konferencia (Conference on "Eszterháza's garden art in black and white"), Fertőd, 2020. October 1-2., Hungary

Van Oosterhout C, Hutchinson WF, Wills DPM, Shipley P (2004) MICROCHECKER: software for identifying and correcting genotyping errors in microsatellite data. Mol Ecol Notes 4:535-538. https://doi.org/10.1111/j.14718286.2004.00684.X

Vanden Broeck A, Cox K, Melosik I, Maes B, Smets K (2018) Genetic diversity loss and homogenization in urban trees: the case of Tilia $\times$ europaea in Belgium and the Netherlands. Biodivers Conserv 27:3777-3792. https://doi.org/ 10.1007/s10531-018-1628-5

Vöröss LZ (1984) János Wagner's Tilia herbarium. Stud Bot Hung 17:69-72

Wickham H (2014) dplyr: a grammar of data manipulation. In Proceedings of the R User Conference, Los Angeles, CA, USA (Vol. 30). https://www.r-project.org/conferences/ useR-2014/files/Abstracts.pdf (Accessed: July 20, 2021)

Wolff K, Hansen OK, Couch S, Moore L, Sander H, Logan SA (2019) Tilia cultivars in historic lime avenues and parks in the UK, Estonia and other European countries. Urb For Urb Green 43:126346. https://doi.org/10.1016/j.ufug. 2019.05.008

Wolff K, Depner B, Logan SA, Heurich M (2021) Informed conservation management of rare tree species needs knowledge of species composition, their genetic characteristics and ecological niche. For Ecol Manage 483:118771. https://doi.org/10.1016/j.foreco.2020.118771

Yousefzadeh H, Hosseinzadeh Colagar A, Tabari M, Sattarian A, Assadi M (2012) Utility of ITS region sequence and structure for molecular identification of Tilia species from Hyrcanian forests. Iran Plant Syst Evol 298:947-961. https://doi.org/10.1007/s00606-012-0604-x

Publisher's Note Springer Nature remains neutral with regard to jurisdictional claims in published maps and institutional affiliations. 